\title{
Extracorporeal membrane oxygenation with multiple-organ failure: Can molecular adsorbent recirculating system therapy improve survival?
}

\author{
Bailey E. Sparks \\ Thomas Jefferson University \\ Nicholas C. Cavarocchi \\ Thomas Jefferson University \\ Hitoshi Hirose \\ Thomas Jefferson University
}

\section{Follow this and additional works at: https://jdc.jefferson.edu/surgeryfp \\ Part of the Surgery Commons \\ Let us know how access to this document benefits you}

\section{Recommended Citation}

Sparks, Bailey E.; Cavarocchi, Nicholas C.; and Hirose, Hitoshi, "Extracorporeal membrane oxygenation with multiple-organ failure: Can molecular adsorbent recirculating system therapy improve survival?" (2017). Department of Surgery Faculty Papers. Paper 145.

https://jdc.jefferson.edu/surgeryfp/145

This Article is brought to you for free and open access by the Jefferson Digital Commons. The Jefferson Digital Commons is a service of Thomas Jefferson University's Center for Teaching and Learning (CTL). The Commons is a showcase for Jefferson books and journals, peer-reviewed scholarly publications, unique historical collections from the University archives, and teaching tools. The Jefferson Digital Commons allows researchers and interested readers anywhere in the world to learn about and keep up to date with Jefferson scholarship. This article has been accepted for inclusion in Department of Surgery Faculty Papers by an authorized administrator of the Jefferson Digital Commons. For more information, please contact: JeffersonDigitalCommons@jefferson.edu. 
EXTRACORPOREAL MEMBRANE OXYGENATION WITH MULTIPLE-ORGAN FAILURE:

CAN MOLECULAR ADSORBENT RECIRCULATING SYSTEM THERAPY IMPROVE SURVIVAL?

Bailey E. Sparks BSN, Nicholas C. Cavarocchi MD, Hitoshi Hirose MD.

From: Division of Cardiothoracic Surgery, Department of Surgery

Thomas Jefferson University, Philadelphia, PA.

Short title: ECMO with MARS.

Total word count: $\mathbf{x x x}$

Key words: ECMO; Multi organ failure; Liver failure; MARS.

Corresponding Author: Hitoshi Hirose, MD.

Department of Surgery, Thomas Jefferson University

607 College Building, 1025 Walnut Street, Philadelphia, PA 19107

Phone: 215-955-6925

Fax: 215-925-6010

Email: genex@nifty.com

This paper was accepted for presentation at 36th Annual Meeting and Scientific Sessions, International Society of Hear and Lung Transplantation, April 2016, Washington DC. 


\begin{abstract}
Background: Liver dialysis, molecular adsorbent recirculating system (MARS) particularly, has been used in liver failure to bridge to transplantation. We expanded the indication for MARS to patients with acute shock liver failure and cardiopulmonary failure on ECMO, aiming to improve survival to wean from ECMO.

Methods: An IRB approved, retrospective chart analysis of patients on ECMO between 2010 and 2015 found 28 patients who met the criteria for acute liver failure, diagnosed by hyperbilirubinemia (total bilirubin $\geq 10 \mathrm{mg} / \mathrm{dl}$ ), or by elevated transaminase (alanine transaminase [ALT] >1000 IU/L). Among those, 14 patients underwent MARS treatment (Group M) and 14 patients were supported with optimal medical treatment without MARS (Group C). Patient characteristics, liver function and survival were compared between groups.
\end{abstract}

Results: Demographics, clinical risk factors, and pre-ECMO laboratory data were identical between the groups. MARS was utilized continuously for $8 \pm 9$ days in Group M. Total bilirubin, ALT, and international normalized ratio (INR) were improved significantly in Group M. There were no MARS-related complications. Survival to wean from ECMO for Group M was 64\% (9/14) versus $21 \%$ (3/14) for Group C, $p=0.02$. Death related to worsening liver dysfunction during ECMO was $40 \%(2 / 5$ deaths) in Group M and 100\% (11/11 deaths) in Group C, p=0.004. Thirty-day survival after ECMO was $43 \%(6 / 14)$ in Group M and 14\% (2/14) in Group C, p=0.09.

Conclusions: MARS therapy on ECMO patients safely accelerated recovery of liver function and improved survival to wean from ECMO, without increasing complications. 


\section{Introduction}

In cases of acute-on-chronic liver failure, liver dialysis, specifically the molecular adsorbent recirculating system (MARS) has been used to bridge patients to liver transplantation and is known to improve outcomes of liver transplantation. ${ }^{1,2}$ MARS therapy consists of filtering blood through a specialized albumin-containing dialysate to remove protein-bound toxins. Blood is filtered in-line through a charcoal column and an anion exchanger column before return. This system allows for the removal of molecules such as bile acids, bilirubin, and cytokines, as well as water-soluble toxins such as

creatinine and ammonia. ${ }^{3}$ By removing both protein-bound and water-soluble toxins, MARS facilitates liver recovery and also may prevent further deterioration of other organ systems. ${ }^{4}$

Overall ECMO mortality is reported to be $47 \%-61 \%,{ }^{5}$ and one of the primary causes of death for extracorporeal membrane oxygenation (ECMO) patients is refractory multiple-organ failure including acute liver failure. Acute liver failure (ALF) occurs in $\sim 13-19 \%$ of the ECMO population. ${ }^{6}$ In our institution, we expanded the indication for MARS to another patient population - cardiopulmonary failure patients requiring ECMO who have developed acute liver failure. This retrospective study was performed to evaluate the questions: can MARS improve acute liver failure on ECMO safely, and to evaluate the survival of the patients with or without MARS treatments on ECMO.

\section{Methods}

After approval from the institutional review board, medical records of consecutive ECMO patients between August 2010 and March 2015 were retrospectively reviewed to identify the incidence of liver dysfunction while on ECMO. The only exclusion criterion was any ECMO patient in whom treatment was deemed futile within the first 24 hours of cannulation. Veno-arterial ECMO (VA ECMO) was primarily used for refractory cardiac failure, ${ }^{7}$ and veno-veno ECMO (VV ECMO) was primarily used for refractory respiratory failure, ${ }^{8}$ detailed in the previous publications.

Among the 133 ECMO patients during the study period, 28 patients (21\%) were found to have acute liver failure, defined as total bilirubin $\geq 10 \mathrm{mg} / \mathrm{dl}$ or alanine aminotransferase (ALT) $\geq 1000 \mathrm{IU} / \mathrm{L}$. Further details for inclusion data are shown in Table 1. These patients were included if they met the 
criteria for liver failure despite correction of an underlying process such as hemolysis or obstructive cholangitis. The rounding attending physician made the decision for the initiation of MARS. Of the 28 studied patients, 14 patients (Group M) underwent liver dialysis using MARS (Gambro, Lakewood, CO, USA), and 14 patients (Group C) were supported with optimal medical therapies. Medical therapies for Group C and Group M included maintenance of appropriate ECMO flow (body surface area x $2.2 \mathrm{~L} / \mathrm{min}$ or above), lactulose treatment, nutrition support (via either enteral tube feeding or total parenteral nutrition), and avoidance of hepatotoxic medications, including statins and Amiodarone. In Group M, the MARS system was run with blood flow rates between $100-150 \mathrm{ml} / \mathrm{min}$ using a standard dual lumen dialysis catheter placed in the femoral vein, using a 25\% albumin dialysate. Treatment was continued until recovery of liver function; specifically, total bilirubin returned to $\leq 7 \mathrm{mg} / \mathrm{dl}$ and/or ALT $\leq 500 \mathrm{IU} / \mathrm{L}$, or the time of ECMO removal. No patient was placed on MARS with the intention to bridge to liver transplantation. The MARS circuit was maintained continuously, excepting for circuit changes needed every 24 hours. Anticoagulation was maintained for a PTT between 45-55 seconds for ECMO regardless the presence of MARS.

Primary study endpoints were survival to wean from ECMO and 30-day survival after ECMO decannulation. A secondary endpoint was the trend of liver function (total bilirubin, alanine aminotransferase [ALT], and international normalized ratio [INR]) during treatments. In addition, bleeding complications and disseminated intravascular coagulopathy (DIC) were monitored during ECMO.

Data were expressed as number with percent and mean with standard deviations. Statistical analysis consisted of two group comparisons between Group M and Group C using Student t-tests for continuous variables and chi-square or Fisher's exact tests for categorical variables. A p-value less than 0.05 was considered to be significant.

\section{Results}

There were 14 patients in Group M and 14 patients in Group C. Baseline characteristics, pre-ECMO clinical risk factors, and laboratory data were compared and were similar between the two 
groups (Table 2). Group C and Group M both include patients from overlapping timeframes - Group C was not from an era prior to availability of MARS therapy.

The laboratory values for the patients at the time criteria of acute liver failure were met are shown in Table 3. MARS therapy was initiated in mean of $5 \pm 4$ days after ECMO was started in Group M. The length of ECMO before the patients met the criteria for acute liver failure in Group C was $7 \pm 6$ days. The average length of MARS on ECMO was $8 \pm 9$ days (range $1-32$ days). After 3 days, total bilirubin average for Group M ( $\mathrm{n}=12)$ decreased by $5.1 \pm 12 \mathrm{mg} / \mathrm{dL}$, while Group C ( $\mathrm{n}=9)$ average total bilirubin increased $2.6 \pm 9 \mathrm{mg} / \mathrm{dl}(\mathrm{p}=0.11)$. By day 7 , the average total bilirubin for Group $\mathrm{M}(\mathrm{n}=11)$ had decreased by $7.9 \pm 15 \mathrm{mg} / \mathrm{dL}$, while in the same time period the average bilirubin for Group $\mathrm{C}$ had increased by $7.5 \pm 6 \mathrm{mg} / \mathrm{dL}(\mathrm{p}=0.01)$. By day 3, ALT for Group M had decreased by $1310 \pm 1851 \mathrm{IU} / \mathrm{L}$ while in Group C the ALT had increased by $320 \pm 733$ IU/L $(\mathrm{p}=0.01)$. Similarly, by day 3 , INR for Group M had decreased by $0.32 \pm 0.5$ while in Group C the INR had only decreased by $0.05 \pm 0.4$ IU/L (p $=0.19$ ). These trends are shown in Figure 1. Furthermore, these trends continued for the duration of ECMO, as shown in Figure 2.

Bleeding complications while on ECMO, defined as bleeding that required invasive intervention, were $79 \%(n=11)$ in both groups. The most common etiologies were gastrointestinal bleeding, epistaxis, and cannula site bleeding; this breakdown was consistent across both groups. Incidence of disseminated intravascular coagulopathy (DIC) was $14 \%(n=2)$ for Group M vs. $21 \%(n=3)$ for Group C $(p=0.62)$. The causes of DIC were multifactorial, and did not appear to be related to MARS treatment. There was no MARS-related sepsis. There were no mechanical ECMO complications, such as flow competition, during MARS.

Survival to wean from ECMO was 64\% (9/14) in Group M and 21\% (3/14) in Group C, p=0.02 (Figure 3). Death related to worsening liver dysfunction was 40\% (2/5 deaths) in Group M and 100\% $(11 / 11$ deaths) in Group $\mathrm{C}(\mathrm{p}=0.004)$. Of the patients to survive to wean off of ECMO, only 2 patients (22\%) in Group M continued MARS treatment and in both of those cases, liver function was eventually normalized. Five patients $(56 \%)$ in Group $\mathrm{M}$ weaned to a permanent mechanical circulatory support 
device, versus only 1 patient $(33 \%)$ in Group $\mathrm{C}(\mathrm{p}=0.06)$. Thirty days survival after ECMO decannulation was 43\% (6/14) in Group M and 14\% (2/14) in Group C, p=0.09 (Figure 3). The patients in Group $\mathrm{M}$ who survived to wean off of ECMO all recovered liver function, therefore liver failure was not a contributing factor to their death.

\section{Discussion}

The research on MARS for patients with cardiopulmonary failure requiring ECMO is very sparse. Zitterman ${ }^{9}$ used MARS for liver failure due to cardiogenic shock following cardiac surgery. The study involved 197 post-operative patients with a bilirubin $>6 \mathrm{mg} / \mathrm{dl}$, of which 20 (10\%) required ECMO. They reported many complications (gastrointestinal, respiratory, and infections) and had an in-hospital mortality rate of $66 \%(n=129)$ after MARS initiation. Total bilirubin did not decrease in their cohort overall, though the survivors did show a significant decrease compared with non-survivors. Based on APACHE II, SOFA, and SAPS II scores, they determined a predicted mortality of $100 \%$, which improved to $34 \%$ (n=68) with MARS usage. ${ }^{9}$ Survival within the ECMO population specifically was not discussed. In the only study specifically involving ECMO patients, Peek ${ }^{10}$ reviewed their series of ECMO prior to the use of MARS and found that no ECMO patients at their institution survived once severe liver dysfunction (total bilirubin $>23 \mathrm{mg} / \mathrm{dl}$ ) developed and only $10 \%$ survived if bilirubin was greater than $17 \mathrm{mg} / \mathrm{dl}$. With this prior survival data, Peek et al. changed their indication to initiate MARS to include patients with bilirubin greater than $17 \mathrm{mg} / \mathrm{dl}$. Using MARS with this indication, 2/5 $(40 \%)$ of the patients survived, compared to a prediction of $100 \%$ mortality. ${ }^{10}$

While we were able to show that survival was improved in Group M versus Group C, it is equally important to note that complications from using the treatment did not arise. In the two cases of DIC within the treatment group, the causes were multifactorial, and did not appear to be related to MARS. One of the patients was an acetaminophen overdose who was never stabilized following cardiac arrest and ECMO, while the other was due to possible hemolysis after a prolonged course on ECMO requiring three different mechanical circulatory support devices. Complications occurring in the ICU course for both 
groups were similar, and specifically, incidence of DIC was similar, with no indication MARS was the cause of any case of DIC.

In another study, Rittler $^{11}$ reviewed 5 patients after Whipple's operation or liver transplantation complicated with liver failure and gram-negative sepsis and/or fungemia. In that particular population with liver failure accompanied by sepsis, despite the use of MARS, no patients survived. They also reported significant bleeding side effects in this group, although they were using heparin to maintain PTT $>50$ seconds to anti-coagulate the MARS system. They concluded that sepsis-related liver failure might not be an indication for MARS therapy. ${ }^{11}$ In our study, sepsis was not the primary cause of shock liver, but 2 patients in Group M (14\%) and 3 patients in Group C (21\%) were septic during the study. The patients in Group M did not have any of the complications seen in the Rittler study. Those 2 patients in Group M survived, while none of the 3 septic patients in Group C survived to wean off of ECMO ( $p=$ $0.03)$.

Prior studies on the effectiveness of MARS in the acute-on-chronic liver failure population have found that treatment can improve hemodynamic status or have an effect on coagulation. ${ }^{1,12}$ We found an improvement of INR while on MARS (Figures $1 \& 2$ ); however, we were not able to identify the hemodynamic improvement, maybe because hemodynamics were already supported by ECMO.

Our study supports that acute liver failure during ECMO can be supported with MARS and that once liver functions are normalized, no additional MARS are necessary. Additionally, the fact that five of the patients in Group M were implanted with ventricular assist devices points to recovery of end organ function, without any neurological deficits. Without recovery of liver function, these patients would not have been device candidates.

The decision to start MARS treatment was most often based upon increased total bilirubin. However, we found the Group M had significantly higher liver enzymes as well. Group M also met criteria for acute liver failure sooner after ECMO initiation ( $3 \pm 3$ days) than Group C ( $6 \pm 7$ days). By day 3 after inclusion, only 70\% (10/14) of the patients in Group C were alive, dropping to 36\% (5/14) survival by day 7. This is compared to $79 \%(11 / 14)$ survival to day 7 in Group $M(p=0.02)$. This 
illustrates that medical therapy alone is not enough to stop the progression from acute liver failure to death in this patient population. All patients in the treatment group showed total bilirubin that trended downward by day 3, and continued downward until MARS was stopped (Figure 2) - suggesting that liver function recovered.

The main limitation of this study was small sample size, retrospective, single center experience. The decision to initiate MARS therapy was a clinical judgment base on the attending physician's assessment at the bedside and thus the two groups were not randomized. This study does not address discharge survival data. Because many surviving patients in Group $\mathrm{M}$ went on to receive permanent mechanical circulatory support devices, they required a more prolonged hospital stay. Survival to discharge data in that group would have many other confounding variables from those other forms of mechanical support devices as well as from the prolonged hospital stay. Going forward, research is needed to further refine the appropriate patient selection criteria and to initiate optimal treatment guidelines, as well as to determine if MARS therapy increases survival to discharge.

\section{Study Highlights}

At this time, the use of MARS liver dialysis for acute-on-chronic liver failure to prolong survival until transplantation has been accepted. ${ }^{1,2}$ However, the research on expanding the use of MARS to other patient populations has demonstrated mixed results, regarding both safety and efficacy. This study looked at a specific population - multiple-organ failure patients on ECMO with acute liver failure - in order to determine if MARS could improve survival to wean off ECMO. The results showed that without increasing complications, MARS could safely improve survival outcomes and accelerate liver recovery within this patient population. ECMO is widely used to support the patient while the heart and/or lungs recover, the results of this study indicate that the liver can recover in the same manner if the patient is supported with the MARS liver dialysis system.

\section{Conclusion}


The results of this study show that the MARS system for liver dialysis can safely and effectively be used for acute liver failure in cardiopulmonary failure patients who are being supported by ECMO in order to accelerate liver recovery. Survival benefit by MARS was clearly demonstrated, without any additional increase in complications.

\section{Financial Conflict of Interest Disclosure}

No conflicts of interest to disclose for any authors. No funding was received for this research. 
Table 1: Inclusion Criteria for MARS on ECMO.

\begin{tabular}{|l|c|c|c|}
\hline & $\begin{array}{c}\text { Group M } \\
(\mathrm{N}=14)\end{array}$ & $\begin{array}{c}\text { Group C } \\
(\mathrm{N}=14)\end{array}$ & $P$ - value \\
\hline Hyperbilirubinemia $(>10 \mathrm{mg} / \mathrm{dl})$ & 11 & 14 & 0.0668 \\
\hline Increased ALT $(>1000 \mathrm{IU} / \mathrm{L})$ & 3 & 0 & 0.0668 \\
\hline Hyperbilirubinemia $(>10 \mathrm{mg} / \mathrm{dl})$ and increased ALT $(>1000 \mathrm{IU} / \mathrm{L})$ & 4 & 2 & 0.3570 \\
\hline
\end{tabular}

ALT: alanine aminotransferase. Data expressed as number. 
Table 2: Baseline Demographics and Indications for ECMO.

\begin{tabular}{|c|c|c|c|}
\hline & Group M (n=14) & Group C $(n=14)$ & P-value \\
\hline Age (years) & $44 \pm 16$ & $54 \pm 13$ & 0.0811 \\
\hline Male & $5(36 \%)$ & $9(64 \%)$ & 0.1306 \\
\hline Body mass index $\left(\mathrm{kg} / \mathrm{m}^{2}\right)$ & $27 \pm 6$ & $28 \pm 5$ & 0.6359 \\
\hline Weight (kg) & $76 \pm 26$ & $78 \pm 21$ & 0.8246 \\
\hline \multicolumn{4}{|l|}{ Clinical risk factors } \\
\hline Smoker & $5(36 \%)$ & $3(21 \%)$ & 0.4028 \\
\hline E-CPR & $3(21 \%)$ & $2(14 \%)$ & 0.6217 \\
\hline Diabetes mellitus & $4(29 \%)$ & $4(29 \%)$ & 1.0000 \\
\hline Coronary artery disease & $4(29 \%)$ & $8(57 \%)$ & 0.1266 \\
\hline Acute myocardial infarction & $3(21 \%)$ & $1(7 \%)$ & 0.2801 \\
\hline Primary respiratory failure & $3(21 \%)$ & $4(29 \%)$ & 0.6625 \\
\hline \multicolumn{4}{|l|}{ Primary Diagnosis for ECMO } \\
\hline Acute on chronic heart failure & $4(29 \%)$ & $3(21 \%)$ & 0.6625 \\
\hline Malignant Arrhythmia & $2(14 \%)$ & $0(0 \%)$ & 0.1422 \\
\hline Takotsubo Cardiomyopathy & $0(0 \%)$ & $2(14 \%)$ & 0.1422 \\
\hline Bacterial Pneumonia & $0(0 \%)$ & $1(7 \%)$ & 0.3085 \\
\hline Interstitial Pneumonitis & $1(7 \%)$ & $0(0 \%)$ & 0.3085 \\
\hline Aspiration Pneumonia & $0(0 \%)$ & $2(14 \%)$ & 0.1422 \\
\hline Viral Pneumonia & $0(0 \%)$ & $1(7 \%)$ & 0.3085 \\
\hline Post-cardiotomy failure & $5(35 \%)$ & $4(29 \%)$ & 0.6857 \\
\hline Acute Myocardial Infarction & $2(14 \%)$ & $1(7 \%)$ & 0.5412 \\
\hline \multicolumn{4}{|l|}{ Pre ECMO laboratory data } \\
\hline Creatinine $(\mathrm{mg} / \mathrm{dl})$ & $1.7 \pm 1$ & $1.8 \pm 0.99$ & 0.7522 \\
\hline Total bilirubin $(\mathrm{mg} / \mathrm{dl})$ & $2.9 \pm 3.1$ & $3.3 \pm 3.2$ & 0.7611 \\
\hline Aspartate aminotransferase (IU/L) & $3198 \pm 9997$ & $784 \pm 1610$ & 0.3984 \\
\hline Alanine aminotransferase (IU/L) & $770 \pm 1884$ & $351 \pm 751$ & 0.4642 \\
\hline Alkaline phosphatase (IU/L) & $139 \pm 100$ & $107 \pm 78$ & 0.3704 \\
\hline Lactate $(\mathrm{mg} / \mathrm{dl})$ & $7.4 \pm 7.5$ & $6.6 \pm 5.2$ & 0.7521 \\
\hline INR & $1.99 \pm 1.10$ & $1.98 \pm 0.89$ & 0.9589 \\
\hline \multicolumn{4}{|l|}{ ECMO data } \\
\hline Veno-arterial ECMO & $11(79 \%)$ & $11(79 \%)$ & 1.0000 \\
\hline Veno-venous ECMO & $3(21 \%)$ & $3(21 \%)$ & 1.0000 \\
\hline Length of ECMO (days) & $17 \pm 9$ & $12 \pm 10$ & 0.1761 \\
\hline \multicolumn{4}{|l|}{ ECMO complications } \\
\hline Bleeding & $10(71 \%)$ & $11(79 \%)$ & 0.6625 \\
\hline Disseminated intravascular coagulopathy & $2(14 \%)$ & $3(21 \%)$ & 0.6217 \\
\hline
\end{tabular}


DIC: disseminated intravascular coagulopathy; E-CPR: extra-corporeal membrane oxygenation assisted cardiopulmonary resuscitation; ECMO: extra-corporeal membrane oxygenation; INR: international normalized ratio

Data are expressed as mean \pm standard deviation or as number (percentage). 
Table 3. Laboratory Data at Inclusion.

\begin{tabular}{|l|c|c|c|}
\hline & $\begin{array}{c}\text { Group M } \\
(\mathrm{N}=14)\end{array}$ & $\begin{array}{c}\text { Group C } \\
(\mathrm{N}=14)\end{array}$ & P-value \\
\hline $\begin{array}{l}\text { Duration of ECMO before MARS in group M and } \\
\text { before met criteria of acute liver failure in group C } \\
\text { (days) }\end{array}$ & $5 \pm 4$ & $7 \pm 6$ & 0.31 \\
\hline On CVVHD pre-MARS & $6(43 \%)$ & $9(64 \%)$ & 0.2556 \\
\hline Creatinine (mg/dl) & $1.3 \pm 0.5$ & $1.3 \pm 0.7$ & 1.0000 \\
\hline Bilirubin (mg/dl) & $10.5 \pm 3.3$ & $11.8 \pm 1.9$ & 0.2128 \\
\hline Aspartate aminotransferase (IU/L) & $9412 \pm 13430$ & $492 \pm 698$ & 0.0199 \\
\hline Alanine aminotransferase (IU/L) & $2271 \pm 2577$ & $193 \pm 210$ & 0.0058 \\
\hline Alkaline phosphatase (IU/L) & $162 \pm 83$ & $113 \pm 47$ & 0.0656 \\
\hline Lactate (mg/dl) & $8.2 \pm 8.0$ & $6.8 \pm 7.5$ & 0.6369 \\
\hline INR & $1.86 \pm 0.57$ & $1.52 \pm 0.43$ & 0.0865 \\
\hline MELD Score & $29 \pm 6$ & $30 \pm 5$ & 0.6359 \\
\hline
\end{tabular}

CVVHD: continuous veno-veno hemodialysis; ECMO: extra-corporeal membrane oxygenation; INR: international normalized ratio; MARS: molecular adsorbent recirculating system; MELD Score: Model for End-Stage Liver Disease Score.

Data expressed as mean \pm standard deviation or as number (percentage). 


\section{Legends of Figures}

Figure 1: 1a) Trends of total bilirubin; 1b) Trends of alanine aminotransferase (ALT); 1c) Trends of international normalized ratio (INR).

Figure 2: $\quad$ 2a) Trends of total bilirubin in Group $\mathrm{M}$; 2b) Trends of alanine aminotransferase (ALT) in Group M; 2c) Trends of international normalized ratio (INR) in Group M.

Figure 3: Survival data. 


\section{References}

${ }^{1}$ Olin P, Hausken J, Foss A, Karlsen TH, Melum E, Haugaa H. Continuous molecular adsorbent recirculating system treatment in 69 patients listed for liver transplantation; a meta-analysis of complications and mortality of extracorporeal membrane oxygenation. Scand J Gastroenterol 2015; 50:1127-34.

${ }^{2}$ Khuroo MS, Khuroo MS, Farahat KL. Molecular adsorbent recirculating system for acute and acute-on-chronic liver failure: A meta-analysis. Liver Transpl 2004;10:1099-106.

3 Tabata S, Cavarocchi NC, Hirose H. Successful management of severe liver failure on venoarterial extracorporeal membrane oxygenation using molecular adsorbent recirculating system. J Heart Lung Transplant 2012;31:1322-1323.

${ }^{4}$ El Banayosy A, Kizner L, Schueler V, Bergmeier S, Cobaugh D, Koerfer R. First use of the molecular adsorbent recirculating system technique on patients with hypoxic liver failure after cardiogenic shock. ASAIO J. 2004;50:332-337.

5 Zangrillo A, Landoni G, Biondi-Zoccai G, et al. A meta-analysis of complications and mortality of extracorporeal membrane oxygenation. Crit Care Resusc 2013;15:172-8.

${ }^{6}$ Combes A, Leprince P, Luyt CE, et al. Outcomes and long-term quality-of-life of patients supported by extracorporeal membrane oxygenation for refractory cardiogenic shock. Crit Care Med 2008;36:1404-11.

${ }^{7}$ Lamb K, Hirose H, Cavarocchi NC. Preparation and technical considerations for percutaneous cannulation for veno-arterial extracorporeal membrane oxygenation. J Cardiac Surg 2013; 28:190-192.

${ }^{8}$ Shaheen A, Tanaka D, Cavarocchi NC, Hirose H. Veno-venous extracorporeal membrane oxygenation (VV ECMO): Indications, Pre-procedural considerations and Technique. J Card Surg $2016 ; 31: 248-252$.

9 Zittermann A, Engel M, Hohnemann S, Kizner L, Gummert JF. Molecular adsorbent recirculating system technique for liver failure due to cardiogenic shock. Thorac Cardiovasc Surg 2013;61:522-529. 
${ }^{10}$ Peek GJ, Killer HM, Sosnowski MA, Firmin RK. Modular extracorporeal life support for multi-organ failure patients. Liver 2002;22 Suppl 2:69-71.

${ }^{11}$ Rittler P, Ketscher C, Inthorn D, Jauch K, Hartl WH. Use of the molecular adsorbent recycling system in the treatment of postoperative hepatic failure and septic multiple organ dysfunction-preliminary results. Liver Int 2004;24:136-141.

12 Mitzner SR, Klammt S, Peszynski P, et al. Improvement of multiple organ functions in hepatorenal syndrome during albumin dialysis with the molecular adsorbent recirculating system. Ther Apher 2001;5:417-422. 